\title{
Pro-oxidative effects of tea and polyphenols, epigallocatechin-3-gallate and epigallocatechin, on G6PD-deficient erythrocytes in vitro
}

\author{
CHUN HAY KO ${ }^{1}$, KAREN $\mathrm{LI}^{2}$, PAK CHEUNG NG ${ }^{2}$, KWOK PUI FUNG ${ }^{1}$, \\ CHUNG LEUNG $\mathrm{LI}^{4}$, RAYMOND PUI-ON WONG ${ }^{2}$, KIT MAN CHUI ${ }^{2}$, \\ GOLDIE JIA-SHI GU ${ }^{2}$, EDMUND YUNG ${ }^{2}$, CHI CHIU WANG ${ }^{3}$ and TAI FAI FOK ${ }^{2}$ \\ ${ }^{1}$ Institute of Chinese Medicine, ${ }^{2}$ Department of Paediatrics and ${ }^{3}$ Department of Obstetric and Gynaecology, \\ The Chinese University of Hong Kong, Shatin, Hong Kong, SAR, China; ${ }^{4}$ Institute of Cellular and \\ Organismic Biology/Genomic Research Center, Academia Sinica, Taipei, Taiwan
}

Received February 10, 2006; Accepted April 13, 2006

\begin{abstract}
Glucose-6-phosphate dehydrogenase (G6PD)deficient subjects are vulnerable to chemical-induced hemolysis if exposed to oxidative agents. Recent studies reported that green tea and its constituents might act as pro-oxidants. Our objective was to investigate effects of tea and its polyphenolic components on the oxidative status of human G6PD-deficient erythrocytes. Erythrocytes of G6PD-deficient $(\mathrm{n}=8)$ and normal $(n=8)$ subjects were incubated with water extracts of 3 types of tea samples (black tea, green tea and decaffeinated green tea extract) and 6 polyphenols. The resulting levels of reduced glutathione (GSH) and glutathione disulphide (GSSG), methemoglobin and plasma hemoglobin were quantified by HPLC and biochemical assays. The tea extracts significantly reduced GSH and increased GSSG levels in G6PD-deficient erythrocytes in a dose-dependent manner $(0.5-10 \mathrm{mg} / \mathrm{ml})$, but not in normal erythrocytes. Similar dose-dependent responses to (-)-epigallocatechin (EGC) and (-)-epigallocatechin-3-gallate (EGCG), but not to the other polyphenols, were observed. In G6PD-deficient cells, GSH was reduced by $43.3 \%$ (EGC at $0.05 \mathrm{mg} / \mathrm{ml}$ ) and $33.3 \%$ (EGCG at $0.5 \mathrm{mg} / \mathrm{ml})$, compared with
\end{abstract}

Correspondence to: Dr Tai Fai Fok, Department of Paediatrics, Prince of Wales Hospital, The Chinese University of Hong Kong, Shatin, NT, Hong Kong, SAR, China

E-mail: taifaifok@cuhk.edu.hk

Abbreviations: G6PD, Glucose-6-phosphate dehydrogenase; GSH, reduced glutathione; GSSG, glutathione disulphide; CAF, Caffeine; C, (-)-catechin; EC, (-)-epicatechin; ECG, (-)-epicatechin3-gallate; EGC, (-)-epigallocatechin; EGCG, (-)-epigallocatechin-3gallate; GA, gallic acid; GTE, decaffeinated green tea extract; MetHb, methemoglobin; Hb, hemoglobin

Key words: G6PD-deficiency, tea extracts, polyphenols, EGC, EGCG, GSH pre-challenged levels. The concentration of methemoglobin was increased significantly when challenged with tea extracts, and EGC. Plasma hemoglobin levels were higher in G6PDdeficient samples after exposure to tea extracts, EGCG, EGC and gallic acid, compared with those in normal blood. Tea extracts and polyphenols significantly altered the oxidative status of G6PD-deficient erythrocytes in vitro as demonstrated by the decrease of GSH, and increased GSSG, methemoglobin and plasma hemoglobin. Our data caution against the excessive consumption of concentrated tea polyphenolic products by G6PD-deficient subjects.

\section{Introduction}

Glucose-6-phosphate dehydrogenase (G6PD) deficiency, a genetic disorder inherited in the $\mathrm{X}$-linked manner, is the most common human enzymopathy $(1,2)$. It is estimated that $>400$ million people are affected by this disorder worldwide. The condition is prevalent in the Mediterranean region, Africa and Southeast Asia. G6PD-deficient subjects are vulnerable to oxidative stress. This predisposes them to chemical-induced hemolysis, if exposed to pro-oxidative agents such as fava bean $(3,4)$, mothball $(5,6)$, henna $(7,8)$, anti-malarial drugs $(9,10)$, and a variety of herbs (11-14).

Tea, the most commonly consumed herb worldwide, has never been incriminated as a hemolytic agent in G6PDdeficient individuals. Most studies on tea and some polyphenolic components have been focused on their beneficial effects on preventing cancers $(15,16)$, cardiovascular diseases $(17,18)$, and neurodegenerative conditions $(19,20)$. It has been suggested that they act as anti-oxidants by trapping peroxyl radicals and inhibiting lipid peroxidation. In vivo studies on animal models demonstrated that green tea decreased the incidence of lung tumorigenesis in A/J mice induced by 4(methylnitrosamino)-1-(3pyridyl)-1-butanone (21). There has been evidence showing that tea and its major active component, epigallocatechin-3-gallate (EGCG) possess inhibitory effects on the progression of $\mathrm{N}$-nitrosodiethylamine-induced liver tumor (22) and 7,12-dimethyl benz(a)anthracene-induced 
mammary tumor in rats (23). In vitro studies demonstrated that tea and some polyphenols inhibited human cancer cells, as illustrated by i) reducing cell proliferation of HCT 116 colorectal and HepG2 hepatocellular carcinoma cells (24); ii) modulating cell-cycle progression of breast cancer MCF-7 cells (25) and iii) inducing apoptosis of SV40-immortalized and Ha-ras gene transformed human bronchial epithelial cell lines (26). Besides their potential anti-cancer properties, tea and polyphenols have been shown to affect lipid metabolism, prevent the appearance of atherosclerotic plaque and reduce the risk of heart disease in a hamster model of atherosclerosis (27). Neuroprotection effect against 1,2,3,6-methyl-phenyltetrahydropyridine-induced dopaminergic neuron degeneration was demonstrated in a mouse model of Parkinson's disease (28), and prevention of neurotoxin-induced cell injury were observed in pheochromocytoma cells and mesencephalic cells in vitro $(29,30)$. Although the potential benefits in the human population have not been substantiated by epidemiological studies (31-33) or clinical trials, an increasing number of dietary supplements and products are available in the health food market. Some of them contain enriched concentrations of polyphenolic components.

More recently, there has been accumulating evidence from in vitro studies on the potential cytotoxic effect of green tea extracts and EGCG. In these studies, they acted as pro-oxidants by generating reactive oxidative species such as hydrogen peroxide in cell-free conditions, and rodent macrophagelike RAW-264.7 and human promyelocytic leukemic HL60 cell lines (34). Hydrogen peroxide produced in the presence of green tea caused significant cytotoxic effects on rat pheochromocytoma PC12 cells in culture (35). Similar prooxidative cytotoxic effects of tea extracts and EGCG were demonstrated in immortalized oral carcinoma cell lines (36). EGCG caused significant depletion of reduced glutathione (GSH) and, in the presence of $\mathrm{Fe}^{2+}$ ions, resulted in lipid peroxidation. Green tea and EGCG also caused oxidative damage in DNA, particularly in the presence of transition metal, $\mathrm{Fe}^{2+}$ or $\mathrm{Cu}^{2+}$ ions $(37,38)$. Increased DNA breakdown and activation of apoptotic markers, caspase-3 and poly-(ADPribose) polymerase in $\mathrm{PC} 12$ cells were demonstrated at higher concentrations of EGCG (39).

GSH plays a key role in protecting the red cell from oxidative damage by eliminating toxic products and reducing oxidized or nitrosylated protein thiols (40). The availability of GSH in situations of oxidative stress is maintained by NADPH-mediated GSH recycling. However, G6PD-deficient red cells are less capable of GSH regeneration because of inefficiency in NADPH production. Therefore, in G6PDdeficient subject, GSH oxidation can result in accumulation of glutathione disulphide (GSSG) and mixed disulfides between protein sulfhydryl groups and GSH to form Sglutathionylated proteins. The decrease of anti-oxidant GSH may lead to formation of methemoglobin and hemolysis.

In order to determine the safety of tea consumption by G6PD-deficient subjects, the present study was designed to investigate effects of tea and its polyphenolic components on the oxidative status of human G6PD-deficient red cells. G6PDdeficient and normal red cells were exposed to tea extracts and its active ingredients, and levels of GSH, GSSG, as well as methemoglobin and plasma hemoglobin were determined.

\section{Materials and methods}

This study was approved by the Clinical Research Ethics Committee, Faculty of Medicine, The Chinese University of Hong Kong.

Chemicals. Black tea (Ceylon Lipton, Sri Lanka) and green tea (Longjing, China) leaves were obtained from commercial sources in the local market of Hong Kong. Decaffeinated green tea extract (GTE) tablet, Sunphenon DCF-1 was provided by Taiyo Kagaku Co. Ltd. (Tokyo, Japan). Caffeine (CAF) and high purity (>98\%) tea polyphenols: (-)-catechin (C), (-)-epicatechin (EC), (-)-epicatechin-3-gallate (ECG), (-)-epigallocatechin-3-gallate (EGCG), (-)-epigallocatechin (EGC) and gallic acid (GA) were purchased from Sigma-Aldrich Corp. (St. Louis, MO, USA). All HPLC grade solvents were obtained from Merck (Whitehouse Station, NJ, USA). All other chemicals were products of Sigma-Aldrich Corporation.

Tea extract preparation. Black and green tea extracts were prepared as previously reported (37). In brief, dry black tea and green tea leaves (each $25 \mathrm{~g}$ ) were brewed 3 times, each with 11 of hot distilled water $\left(80^{\circ} \mathrm{C}\right)$ for $15 \mathrm{~min}$. The infusion was then cooled to room temperature and filtered with cellulose filter paper $(0.45 \mu \mathrm{m})$ (Millipore, Billerica, MA, USA). The filtrate was then concentrated and evaporated using a vacuum rotary evaporator. The resulting extracts were freeze-dried overnight to produce tea powder.

High performance liquid chromatography (HPLC) analysis of tea extracts. HPLC analyses were performed using a dualpump Beckman System Gold 125 solvent module equipped with a 507 autosampler and a 168 diode array detector (Beckman Instrument Inc., Fullerton, CA, USA). The system was monitored by a computer equipped with the 32 Karat Software (Beckman Instrument Inc.) for data collection, integration and analysis. Tea extracts were injected onto an Ultrasphere ODS column (250x4.6 mm i.d., particle size $5 \mu \mathrm{m})$ (Beckman Instrument Inc.). All solvents were pre-filtered with $0.45 \mu \mathrm{m}$ Millipore filter disk (Millipore) and degassed. A gradient elution was carried out using the following solvent systems: mobile phase A, double distilled water/methanol/ formic acid $(74.7 / 25 / 0.3 ; \mathrm{v} / \mathrm{v} / \mathrm{v})$; mobile phase $\mathrm{B}$, acetonitrile/ formic acid $(99.7 / 0.3 ; \mathrm{v} / \mathrm{v})$. The linear gradient elution system was: $100 \%$ A for $8 \mathrm{~min}$, to $100 \%$ B for $33 \mathrm{~min}$, standing at $100 \% \mathrm{~B}$ for $5 \mathrm{~min}$ and returning to $100 \% \mathrm{~A}$, for another $5 \mathrm{~min}$. The flow rate was $1.0 \mathrm{ml} / \mathrm{min}$ and quantification of the tea polyphenols was performed at $270 \mathrm{~nm}$. Each sample $(20 \mu \mathrm{l})$ was injected into the column after filtration through a $0.45 \mu \mathrm{m}$ filter disk (41).

Identification of the tea polyphenols was carried out by comparing the retention times and the UV absorbance of the unknown peaks to those of the standards. A standard mixture containing GA $(0.06094 \mathrm{mg} / \mathrm{ml})$, EGC $(0.375 \mathrm{mg} / \mathrm{ml}), \mathrm{C}$ $(0.140 \mathrm{mg} / \mathrm{ml})$, EGCG $(0.131 \mathrm{mg} / \mathrm{ml})$, CAF $(0.031 \mathrm{mg} / \mathrm{ml})$, EC $(0.288 \mathrm{mg} / \mathrm{ml})$ and ECG $(0.206 \mathrm{mg} / \mathrm{ml})$ in double distilled water/formic acid 99.7/0.3 (v/v) was prepared and analyzed. Calibration curves for GA, EGC, C, EGCG, CAF, EC and ECG (all $\mathrm{R}^{2}=0.999$ ) were carried out using standard solutions injecting with volumes: 5, 10, and $20 \mu 1$, and analyzed by 
Table I. Composition of individual components in black tea, green tea and GTE.

\begin{tabular}{lccc}
\hline & Black tea, $\%^{\mathrm{a}}$ & Green tea, $\%^{\mathrm{a}}$ & ${\text { GTE, } \%^{\mathrm{b}}}^{\mathrm{a}}$ \\
\hline Gallic acid & $0.433 \pm 0.004$ & $0.665 \pm 0.001$ & $1.391 \pm 0.004$ \\
Caffeine & $3.180 \pm 0.019$ & $3.461 \pm 0.006$ & $0.842 \pm 0.003$ \\
C & $0.812 \pm 0.483$ & $0.407 \pm 0.003$ & $1.366 \pm 0.009$ \\
EC & $0.568 \pm 0.005$ & $0.633 \pm 0.029$ & $5.866 \pm 0.036$ \\
ECG & $1.328 \pm 0.003$ & $2.240 \pm 0.006$ & $13.419 \pm 0.057$ \\
EGC & $0.491 \pm 0.013$ & $0.965 \pm 0.127$ & $12.784 \pm 0.129$ \\
EGCG & $0.801 \pm 0.016$ & $6.076 \pm 0.021$ & $18.661 \pm 0.057$ \\
Total polyphenols & $4.000 \pm 0.520$ & $10.321 \pm 0.186$ & $52.096 \pm 0.288$ \\
\hline
\end{tabular}

${ }^{\mathrm{a}}$ Data are expressed as \% (w/w) dry weight of tea leaves $(\mathrm{n}=3) .{ }^{\mathrm{b}}$ Data are expressed as \% (w/w) weight of GTE tablet $(\mathrm{n}=3) .{ }^{\mathrm{c}}$ Total polyphenols are equal to the sum of $\mathrm{C}, \mathrm{EC}, \mathrm{ECG}, \mathrm{EGC}$ and EGCG.

HPLC. All aqueous solutions of tea extracts were prepared in duplicates and analyzed in two separate experiments.

Subject recruitment. Human blood samples were collected by venipuncture with informed consent from 8 G6PD-deficient and 8 healthy adult male volunteers. Each blood sample was gently mixed with anti-coagulant adenine citrate dextrose (ACD). All analyses were carried out within $24 \mathrm{~h}$.

G6PD assay. The G6PD levels of whole blood samples were determined by a commercially available G6PD diagnostic kit (Trinity Biotech Plc., Co Wicklow, Ireland), based on the production of NADPH and its absorption in the UV spectrum $(\lambda=340 \mathrm{~nm})$. Individuals with G6PD activity $\leq 2 \mathrm{U} / \mathrm{g} \mathrm{Hb}$ were considered as deficient (2).

Challenge of red blood cells with water-soluble extracts from tea leaves, and tea polyphenols. Normal or G6PD-deficient whole blood samples $(300 \mu \mathrm{l})$ were incubated with different concentrations of the challenging agents in $\mathrm{PBS}$, at $37^{\circ} \mathrm{C}$ with shaking for $2 \mathrm{~h}$ (37). These agents included tea extracts (black tea, green tea and GTE), tea polyphenols (C, EC, ECG, EGCG, EGC and GA), as well as $\alpha$-naphthol at $0.1 \mathrm{mg} / \mathrm{ml}$ (positive control). This dosage of $\alpha$-naphthol was established to produce significant hemolytic effects on G6PD-deficient red blood cells in a pilot study.

Determination of GSH and GSSG by HPLC. GSH and GSSG levels in whole blood samples were determined by HPLC according to a described method (40). Each treatment sample (175 $\mu \mathrm{l}$ ) was reacted with $17.5 \mu \mathrm{l}$ N-ethylmaleimide (NEM, $310 \mathrm{mmole} / \mathrm{l})$ for $5 \mathrm{sec}$. The mixture was diluted with an equal volume $(192.5 \mu 1)$ of $5 \%(\mathrm{w} / \mathrm{v})$ trichloroacetic acid (TCA) and centrifuged at 15,000 x $\mathrm{g}$ for $2 \mathrm{~min}$. The excess NEM was extracted from the clear supernatant with 10 volumes of dichloromethane. The supernatant $(200 \mu 1)$ was mixed with $100 \mu 1$ Tris-Cl 1 mole/l, $\mathrm{pH} 10.0$ for alkalization. Each mixture was reacted with an equal volume of $1.5 \%(\mathrm{v} / \mathrm{v}) 2,4-$ dinitrofluorobenzene (FDNB) solution for $3 \mathrm{~h}$ at room temperature in the dark. After acidification with $20 \mu \mathrm{l}(\mathrm{v} / \mathrm{v})$ $37 \% \mathrm{HCl}$, the mixture was filtered and loaded onto the Prevail amino $\left(-\mathrm{NH}_{2}\right)$ HPLC column $(250 \times 4.6 \mathrm{~mm}$ i.d., particle size $5 \mu \mathrm{m})$ (Alltech, Deerfield, IL, USA) with pre-running into a guard column $(7.5 \times 4.6 \mathrm{~mm})$. A gradient elution was carried out using solvent A (double distilled water/methanol, 20/80; v/v) and solvent B (sodium acetate/solvent A, 4.1/100; w/v, $\mathrm{pH}$ 4.6). The elution system was $30 \%$ solvent $\mathrm{A}$ for $10 \mathrm{~min}$, and followed by a linear gradient of $30-95 \%$ solvent B for 10-35 min. A constant flow rate of $1 \mathrm{ml} / \mathrm{min}$ was applied. Detection was performed with a UV detector set at $355 \mathrm{~nm}$. Each treatment sample was prepared in duplicate and analyzed by HPLC. By comparing the retention time and area under curve of the peaks with those of standard GSH and GSSG in different concentrations, the concentrations of GSH and GSSG in the whole blood sample were determined.

Methemoglobin determination. Each treatment sample (10 $\mu \mathrm{l})$ was diluted with distilled water $(1 \mathrm{ml})$ and divided into two equal volumes (A and B). For portion A, the absorbance change $(630 \mathrm{~nm})$ was determined before and after adding of $20 \mu \mathrm{l}$ of potassium cyanide (KCN) (42). For portion B, $20 \mu \mathrm{l}$ of potassium ferricyanide $\mathrm{K}_{3}\left[\mathrm{Fe}(\mathrm{CN})_{6}\right]$ was added. The absorbance change was determined before and after the addition of $20 \mu \mathrm{l}$ of $\mathrm{KCN}$. The percentage methemoglobin (MetHb) was calculated by dividing the absorbance change of portion A with that of portion B.

Plasma hemoglobin determination. Plasma was isolated from blood samples by centrifugation $\left(3,000 \mathrm{xg}, 4^{\circ} \mathrm{C}\right)$ for $10 \mathrm{~min}$. The absorbance of plasma hemoglobin $(\mathrm{Hb})$ was determined at $540 \mathrm{~nm}$ and compared with the standard curve of hemoglobin. The result was expressed as $\mathrm{g} \mathrm{Hb} / \mathrm{dl}$ (43).

Statistical analysis. The differences between treatment and control groups (not exposed to tea extracts or its polyphenols) were tested by one-way ANOVA, followed by posthoc Dunnet's test. The differences between the deficient groups and respective normal groups were analyzed for significance by Student's t-test. All statistical analyses were performed by using the Statistical Package of Social Science (SPSS) version 13.0 for Windows (SPSS Inc., Chicago, IL, USA). All statistical tests were carried out at the $5 \%$ level of 
Table II. GSH levels of G6PD-deficient erythrocytes upon challenge with $0.1 \mathrm{mg} / \mathrm{ml} \alpha$-naphthol.

\begin{tabular}{lccc}
\hline Patient No. & $\begin{array}{c}\text { G6PD level, } \\
\mathrm{U}^{\prime} \text { Hb }^{\mathrm{a}}\end{array}$ & $\begin{array}{c}\text { Baseline GSH level, } \\
\mathrm{mg} / \mathrm{dl} \mathrm{RBC}^{\mathrm{a}}\end{array}$ & $\begin{array}{c}\text { \% Change in GSH upon } \\
\text { - }\end{array}$ \\
\hline 1 & 1.6 & 68.6 & 68.1 \\
2 & 1.3 & 66.3 & 61.3 \\
3 & 0.7 & 64.9 & 61.3 \\
4 & 0.5 & 49.9 & 78.8 \\
5 & 0.4 & 58.8 & 49.6 \\
6 & 0.5 & 64.6 & 58.9 \\
7 & 1.5 & 52.4 & 78.8 \\
8 & 1.6 & 72.2 & 68.1 \\
Deficient group & $1.01 \pm 0.19^{\mathrm{b}}$ & $62.2 \pm 2.8$ & $65.6 \pm 3.5^{\mathrm{c}}$ \\
Normal group & $10.9 \pm 0.43$ & $64.1 \pm 2.5$ & $2.4 \pm 0.9^{\mathrm{c}}$ \\
\hline
\end{tabular}

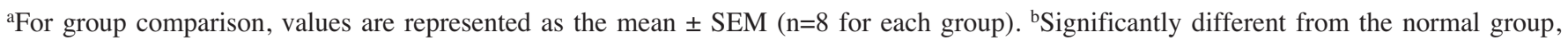
$\mathrm{P}<0.001$. 'Significantly different from baseline GSH level without $\alpha$-naphthol challenge, $\mathrm{P}<0.001$.
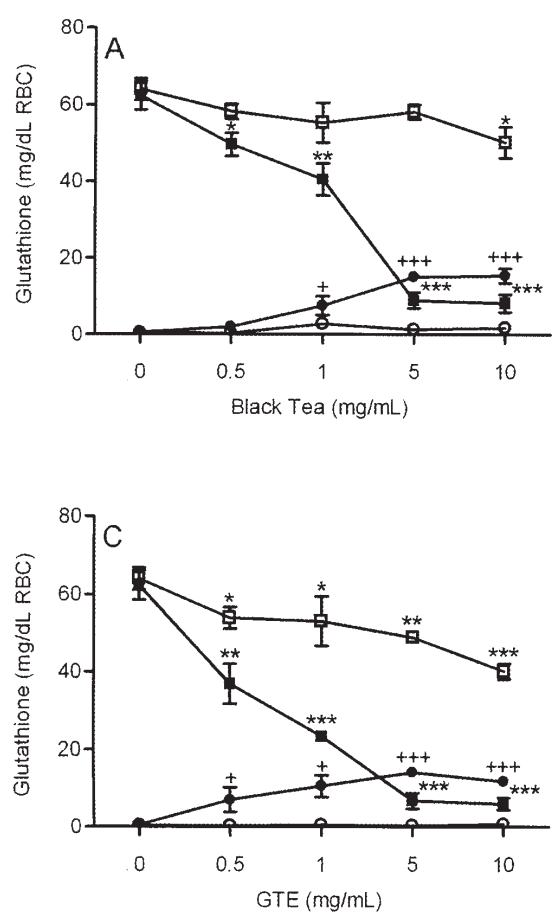

significance $(\mathrm{P}<0.05)$. Data are expressed as means \pm standard error of the mean (SEM).

\section{Results}

Components of tea extracts. The compositions of polyphenols in the soluble extracts of black tea, green tea and GTE as determined by HPLC are shown in Table I. In these samples, EGCG was most abundant, followed by ECG, EGC and EC. Whilst black tea and green tea extracts had similar composition and distribution of polyphenols, GTE contained much higher contents of all types of polyphenols. Relatively high caffeine concentrations were found in black tea and green tea extracts, but not in GTE, which was decaffeinated by the manufacturer.

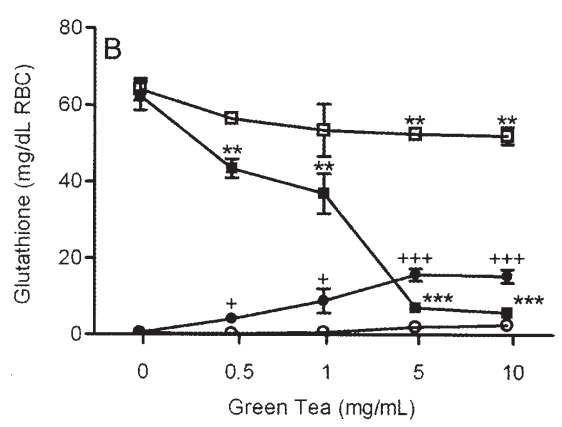

Figure 1. Dose effect of black tea extract (A), green tea extract (B) or GTE (C) on i) GSH level in G6PD-deficient ( $\square$ ) and normal ( $\square$ ) erythrocytes; ii) GSSG level in G6PD-deficient $(\bullet)$ and normal $(\circ)$ erythrocytes. Data are the means (SEM; error bars) from 8 subjects in each group. Significant difference: ${ }^{*} \mathrm{P}<0.05 ;{ }^{* *} \mathrm{P}<0.01 ;{ }^{* * *} \mathrm{P}<0.001$ for difference in $\mathrm{GSH}$ levels from respective baseline cultures without tea extracts. ${ }^{+} \mathrm{P}<0.05 ;{ }^{++} \mathrm{P}<0.01$; ${ }^{+++} \mathrm{P}<0.001$ for difference in GSSG levels from respective baseline cultures without tea extracts.

GSH concentration in G6PD-deficient erythrocytes before and after exposure to $\alpha$-naphthol. G6PD activities in the normal subjects were significantly higher than those of G6PDdeficient subjects $(\mathrm{P}<0.001$, Table II). However, their baseline GSH concentrations were similar. Upon challenge with $\alpha$-naphthol at $0.1 \mathrm{mg} / \mathrm{ml}$, there was significant decrease of GSH $(\mathrm{P}<0.001)$ in G6PD-deficient erythrocytes. Normal erythrocytes were not significantly affected by $\alpha$-naphthol. All G6PD-deficient subjects were hemizygous males with molecular defects either of Canton $(50 \%, n=4)$ or Kaiping $(50 \%, n=4)$ genotype, which were considered as severe G6PD deficiency (class 2) in WHO classification (2).

Effects of tea extracts and polyphenols on GSH and GSSG levels. Similar levels of GSH and GSSG were observed in 

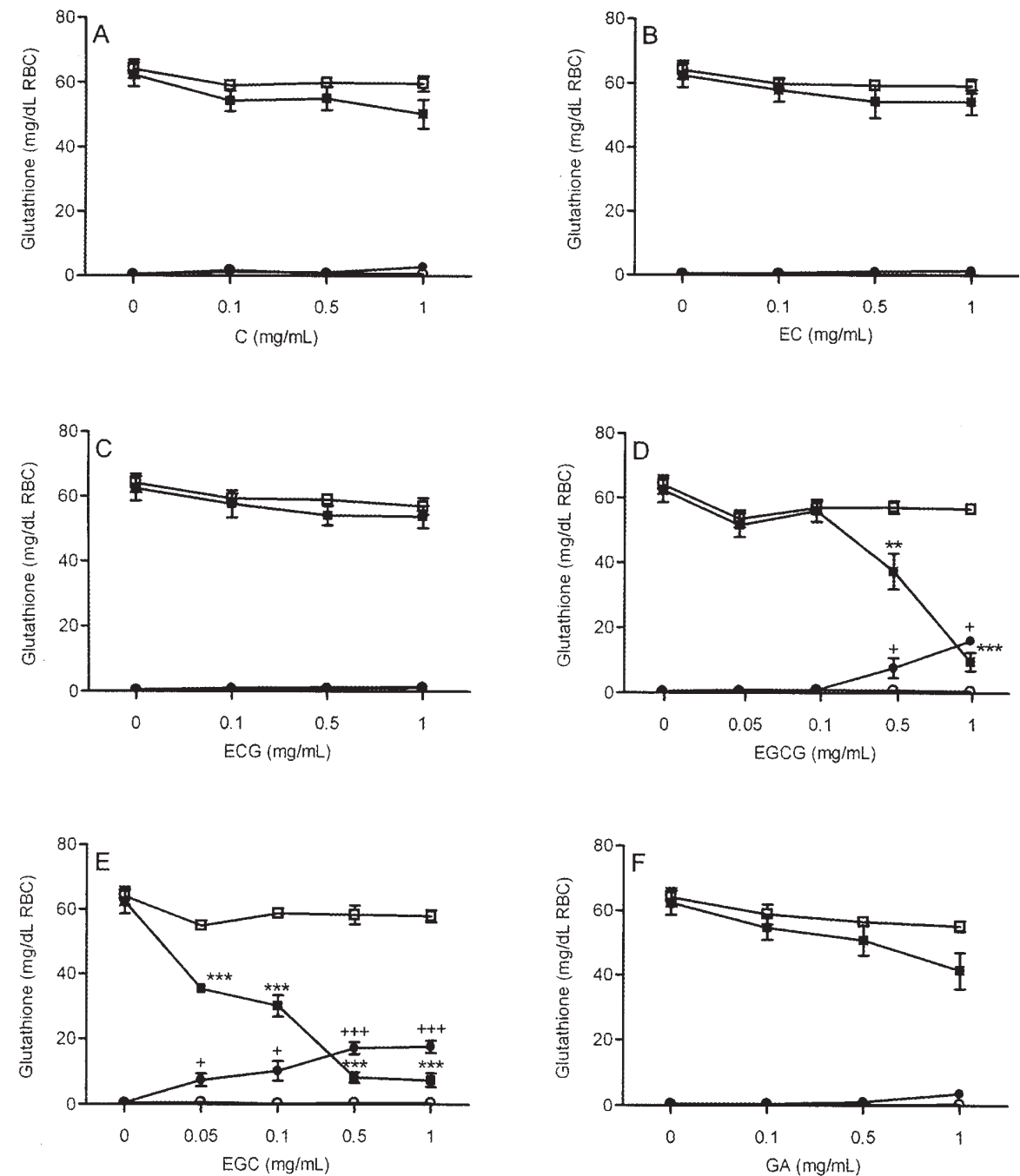

Figure 2. Dose effect of C (A), EC (B), ECG (C), EGCG (D), EGC (E) or GA (F) on i) GSH level in G6PD-deficient (ロ) and normal ( $\square$ ) erythrocytes; ii) GSSG level in G6PD-deficient $(\bullet)$ and normal ( $)$ erythrocytes. Data are the means (SEM; error bars) from 8 subjects in each group. Significant difference: ${ }^{* * *} \mathrm{P}<0.01 ;{ }^{* * *} \mathrm{P}<0.001$ for difference in GSH levels from respective baseline cultures without tea polyphenols. ${ }^{+} \mathrm{P}<0.05 ;{ }^{++} \mathrm{P}<0.001$ for difference in GSSG levels from respective baseline cultures without tea polyphenols.

both normal and G6PD-deficient erythrocytes that were not challenged by tea extracts or their polyphenols components (control) (Fig. 1). A slight albeit statistically significant decrease of GSH levels was observed in normal erythrocytes with increasing concentrations of black tea $(10 \mathrm{mg} / \mathrm{ml}$, $\mathrm{P}=0.021)$, green tea $(5 \mathrm{mg} / \mathrm{ml}, \mathrm{P}=0.009$ and $10 \mathrm{mg} / \mathrm{ml}$, $\mathrm{P}=0.009$ ) and GTE (all concentrations, $\mathrm{P}=0.0001-0.031$ ), when compared with respective controls. However, GSSG was not affected by the presence of any tea extracts in these normal cells. In contrast, green tea and GTE significantly reduced GSH levels in the G6PD-deficient erythrocytes (all concentrations, $\mathrm{P}=0.0001-0.024)$. A similar effect was demonstrated in the black tea group but significant results were not observed at $0.5 \mathrm{mg} / \mathrm{ml}$. In parallel, significant responses to tea extracts were seen in the increase of GSSG level $(\mathrm{P}=0.0001-0.046)$. The percentage decrease of GSH and increase of GSSG concentration in G6PD-deficient groups were significantly different from the respective normal groups at all concentrations $(\mathrm{P}=0.0001-0.047)$ in all tea samples. At $0.5 \mathrm{mg} / \mathrm{ml}$ of black tea (Fig. 1A), green tea (Fig. 1B) or GTE (Fig. 1C), GSH levels in G6PD-deficient erythrocytes were decreased by $20.5 \pm 4.8 \%, 30.4 \pm 4.5 \%$ and $41.0 \pm 6.4 \%$, respectively, whilst
GSSG levels were increased by 3.7 \pm 0.2 -fold, $8.6 \pm 1.1$-fold and $16.7 \pm 3.2$-fold

Similar dose-related responses to EGCG (Fig. 2D) and EGC (Fig. 2E), but not to C, EC, ECG and GA, were observed. The lowest EGC concentration that significantly decreased GSH level (by $43.3 \pm 4.0 \%, \mathrm{P}<0.001$ ) and increased GSSG level (by $21.8 \pm 2.0$-fold, $\mathrm{P}=0.017$ ) was $0.05 \mathrm{mg} / \mathrm{ml}$. For EGCG, $0.5 \mathrm{mg} / \mathrm{ml}$ was the effective dose that regulated these glutathione (GSH decreased by $33.3 \pm 6.6 \%, \mathrm{P}=0.005$, GSSG increased by $17.8 \pm 3.1$-fold, $\mathrm{P}=0.044)$.

Effects of tea extracts and polyphenols on levels of methemoglobin. The addition of tea extracts and polyphenols at all concentrations had no effect on methemoglobin formation in normal erythrocytes (Figs. 3 and 4). In contrast, methemoglobin levels were increased significantly by $5.6 \pm 0.6 \%(10 \mathrm{mg} /$ $\mathrm{ml}, \mathrm{P}=0.016), 2.4 \pm 0.6 \%(5 \mathrm{mg} / \mathrm{ml}, \mathrm{P}=0.009)$ and $5.5 \pm 1.3 \%$ $(5 \mathrm{mg} / \mathrm{ml}, \mathrm{P}=0.008)$ in the presence of black tea (Fig. 3A), green tea (Fig. 3B) and GTE (Fig. 3C), respectively. At $1 \mathrm{mg} /$ $\mathrm{ml}$, EGC significantly increased methemoglobin in G6PDdeficient erythrocytes by $3.9 \pm 0.6 \%$. Other tea polyphenols had no effect on methemoglobin levels (Fig. 4). 

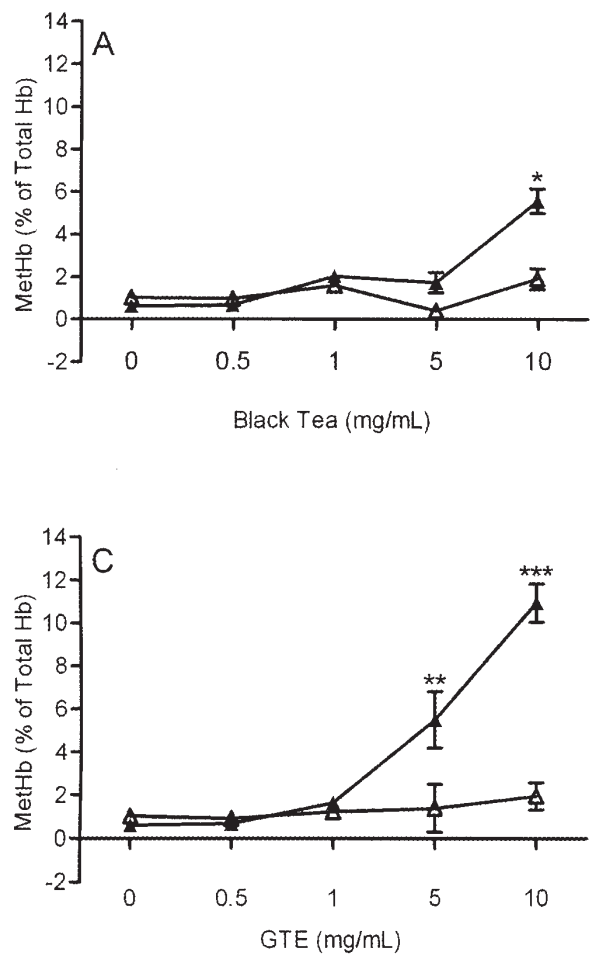

Effects of tea extracts and polyphenols on plasma hemoglobin level. The hemolytic effects of tea and polyphenols were determined by the measurement of hemoglobin released into plasma during incubation of normal and G6PD-deficient blood samples. When $0.5 \mathrm{mg} / \mathrm{ml}$ black tea, green tea or GTE were added to whole blood samples from normal subjects, the plasma hemoglobin levels remained low at $0.02 \pm 0.003$, $0.04 \pm 0.006$ and $0.07 \pm 0.019 \mathrm{~g} / \mathrm{dl}$, respectively which were not different from that in the control (Fig. 5A). However, liberated hemoglobin levels were significantly increased in G6PD-deficient samples, particularly in the GTE group $(0.51 \pm 0.039 \mathrm{~g} / \mathrm{dl}, \mathrm{P}=0.002)$, compared with respective control samples not exposed to tea extracts. With the addition of EGCG, EGC or GA, significant hemolytic effects were observed in the G6PD-deficient sample ( $\mathrm{P}=0.002-0.043)$, but not in the normal blood samples. At this concentration, C, EC and ECG did not exert hemolytic effect on either group of blood samples.

\section{Discussion}

In our present study, compositions of polyphenols in the Ceylon black tea, Longjing green tea and decaffeinated green tea extract as determined by HPLC were in line with those reported previously $(41,44)$. We showed that these tea extracts and two of their polyphenol components (EGC and EGCG) significantly altered the redox status of G6PD-deficient erythrocytes. This was indicated by reduction in the GSH level, increased GSSG level and elevated methemoglobin concentration, following the addition of the tea extracts, EGC or EGCG to the G6PD-deficient blood samples. Lysis of red cells was confirmed by an increase in plasma hemoglobin level. These are sequential events that would take place when G6PD-deficient red cells are exposed to pro-oxidants.

In contrast, no similar change was observed when the tea extracts or tea polyphenolic components were added to normal

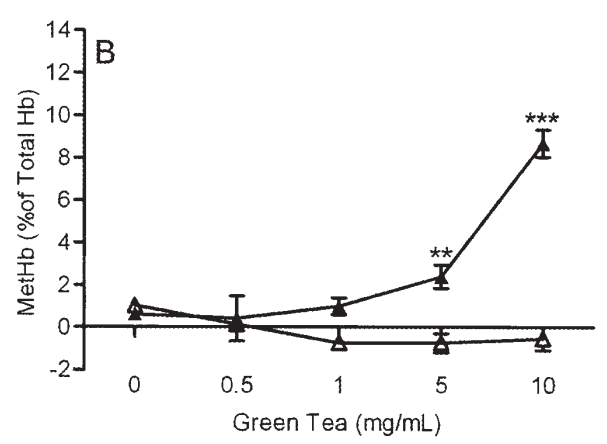

Figure 3. Effect of tea extracts on methemoglobin level of G6PD-deficient $(\Delta)$ and normal $(\triangle)$ erythrocytes. Data are the means (SEM; error bars) from 8 subjects in each group. Significant difference: ${ }^{*} \mathrm{P}<0.05 ;{ }^{* *} \mathrm{P}<0.01 ;{ }^{* * *} \mathrm{P}<0.001$ for difference in methemoglobin level (MetHb) from respective baseline cultures without tea extracts.

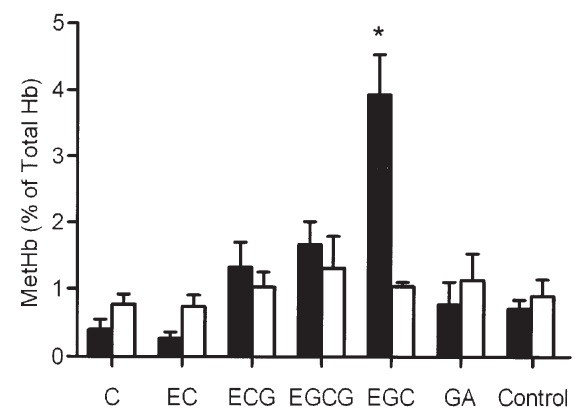

Figure 4. Effect of tea polyphenols on methemoglobin levels in G6PDdeficient ( $\square$ ) and normal $(\square)$ erythrocytes at $0.5 \mathrm{mg} / \mathrm{ml}$. Data are the means (SEM; error bars) from 8 subjects in each group. Significant difference: ${ }^{*} \mathrm{P}<0.05$ for difference in methemoglobin level (MetHb) from respective baseline cultures without tea polyphenols.

erythrocytes, presumably as a result of their capacity to maintain GSH level and to generate NADPH by the pentose phosphate pathway. Among the tea extracts investigated in our study, their oxidative activity had a direct relationship to their EGC or EGCG concentration, which was highest in the decaffeinated green tea extract. ECG, another important polyphenol component of tea extracts, did not have any effect on the GSH and GSSG levels of the G6PD-deficient erythrocytes. This phenomenon could be explained by the structural differences of the polyphenols. Miura et al demonstrated that flavonoids with pyrogallol-structure generated more $\mathrm{H}_{2} \mathrm{O}_{2}$ than catechol-structures (45). EGC and EGCG are pyrogallol-type polyphenols and they were shown to generate $\mathrm{H}_{2} \mathrm{O}_{2}$ under aerobic conditions (46). In contrast, catechol-type polyphenols EC and ECG did not exhibit any pro-oxidative activity.

Our data are in accordance with reports on the prooxidative activities of black tea, green tea, EGC and EGCG 

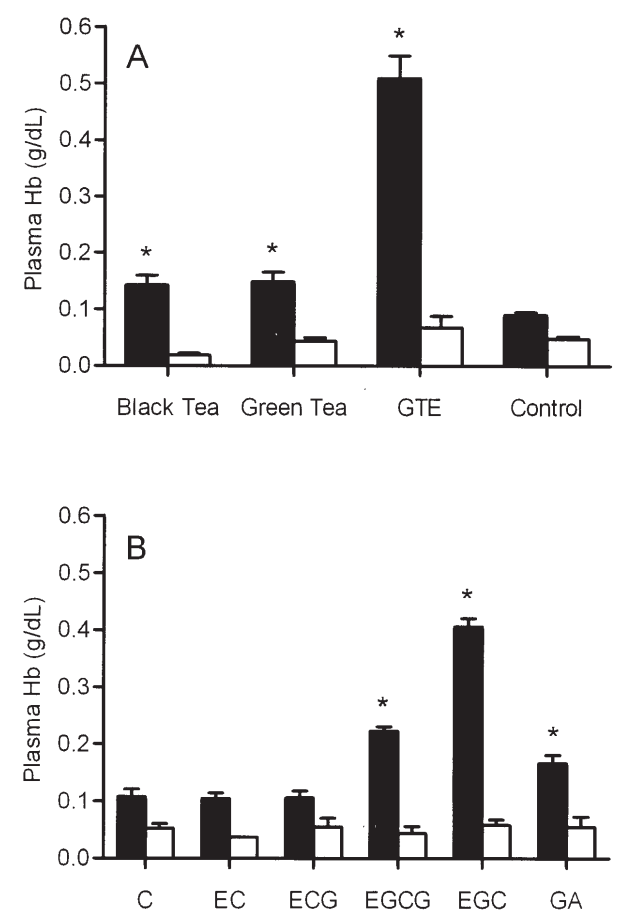

Figure 5. Effect of tea (A) and polyphenols (B) on the plasma hemoglobin concentration in G6PD-deficient ( $\square$ ) and normal $(\square)$ erythrocytes. Whole blood samples were incubated with PBS (control), or tea extracts and polyphenols at $0.5 \mathrm{mg} / \mathrm{ml}$ at $37^{\circ} \mathrm{C}$ for $2 \mathrm{~h}$. Data are the means (SEM; error bars) from 8 subjects in each group. Significant difference: ${ }^{*} \mathrm{P}<0.05$ for difference in plasma hemoglobin level from respective baseline cultures without tea polyphenols.

on various cancer cell lines (34-36). In in vitro cultures as well as in cell-free systems $(34,46,47)$, the production of hydrogen peroxide from tea and its components has been detected. The resulting cellular damage included the depletion of $\mathrm{GSH}$, increased lipid peroxidation, DNA cleavage and cell death. However, the oxidative effects of tea and its components on cellular systems in vitro have been controversial as other reports suggested their anti-oxidative properties (48-50). A recent study on normal and diabetic erythrocytes demonstrated that all members of tea polyphenols at $10 \mu \mathrm{M}$ decreased tertbutyl hydroperoxide-induced GSH depletion (51). Moreover, these polyphenols had little effect on GSH levels of erythrocytes that were not challenged by the pro-oxidant.

To date, there has been no evidence that the intake of green or black tea induces noticeable hemolytic effects in G6PDdeficient subjects. One reason might be the rather low bioavailability of tea polyphenols in human. Several pharmacokinetics studies on single-dose orally administered green tea and polyphenols reported that EGC and EGCG had relatively poor absorption. Lee et al (52) observed that oral administration of $20 \mathrm{mg}$ green tea extract $/ \mathrm{kg}$ body weight resulted in maximal plasma concentration $\left(\mathrm{C}_{\max }\right)$ of EGC and EGCG at $223 \mathrm{ng} / \mathrm{ml}$ and $77.9 \mathrm{ng} / \mathrm{ml}$ at $1.3-1.6 \mathrm{~h}$ post-consumption, respectively. The half-lives of EGC and EGCG were $1.7 \mathrm{~h}$ and $3.4 \mathrm{~h}$, respectively. The plasma EGC was mainly in the conjugated form whereas $77 \%$ of the EGCG was in the free form. In another study (53), oral administration of single dose (800 mg) EGCG and Polyphenon E (decaffeinated green tea catechin mixture, EGCG:EGC:EC in the ratio of 20:3.7:3.1) resulted in $\mathrm{C}_{\max }$ of EGCG at $438.5 \mathrm{ng} / \mathrm{ml}$ and $377.6 \mathrm{ng} / \mathrm{ml}$, respectively. EGC was present at a low level $(<10 \mathrm{ng} / \mathrm{ml})$ after Polyphenon E administration. This dose of Polyphenon E was equivalent to a single consumption of 8 cups of green tea. High concentrations of EGC glucuronide/sulfate conjugates were found in plasma and urine samples after Polyphenon E administration whereas most of the EGCG remained in a free form. Similar plasma levels of polyphenols were observed in subjects who consumed EGCG and Polyphenon E daily for 4 weeks, with some experiencing mild adverse gastrointestinal effects (54). Similar results were demonstrated after consumption of a single dose of Polyphenon E (618 mg of EGCG) or purified EGCG (580 mg of EGCG) by healthy individuals, resulting in plasma $\mathrm{C}_{\max }$ levels of EGCG at $700 \mathrm{ng}$ / $\mathrm{ml}$ and $500 \mathrm{ng} / \mathrm{ml}$, respectively (55). In this context, the concentrations of tea extracts and polyphenols used in this and other in vitro studies (24-30) would not be achievable in the plasma of subjects who consume tea in a normal manner.

In summary, our results present the first evidence on the pro-oxidative actions of tea extracts, EGC and EGCG on G6PD-deficient blood as demonstrated by the reduction of red cell GSH, and increase of GSSG, methemoglobin and plasma hemoglobin. Although it is highly unlikely the plasma concentration of these compounds would reach a harmful level under normal consumption, their pharmacokinetics in G6PD-deficient subjects is unclear. Nevertheless, an additive effect might occur when G6PD-deficient-subjects take additional oxidative drugs. In response to increasing evidence on beneficial effect of tea polyphenols for a variety of diseases, it is anticipated that various highly purified tea polyphenols and pharmaceutical products will soon be made available. Our data caution against the excessive intake of tea polyphenols by G6PD-deficient subjects.

\section{Acknowledgements}

We express our sincere thanks to Mr. Eric Wong, for technical assistance on statistical analysis of data; Ms. Kam Lin Cho and Ms. Sau Wan Cheng, for their technical support in HPLC operations.

\section{References}

1. Beutler E: G6PD deficiency. Blood 84: 3613-3636, 1994.

2. Fok TF, Lau SP and Fung KP: Cord blood G-6-PD activity by quantitative enzyme assay and fluorescent spot test in Chinese neonates. Aust Paediatr J 21: 23-25, 1995.

3. Shibuya A, Hirono A, Ishii S, Fujii $\mathrm{H}$ and Miwa S: Hemolytic crisis after excessive ingestion of fava beans in a male infant with G6PD Canton. Int J Hematol 70: 233-235, 1999.

4. Calabro V, Cascone A, Malaspina P and Battistuzzi G: Glucose6-phosphate dehydrogenase (G6PD) deficiency in southern Italy: a case of G6PD A(-) associated with favism. Haematologica 74: 71-73, 1989.

5. Santucci K and Shah B: Association of naphthalene with acute hemolytic anemia. Acad Emerg Med 7: 42-47, 2000.

6. Todisco V, Lamour J and Finberg L: Hemolysis from exposure to naphthalene mothballs. N Engl J Med 325: 1660-1661, 1991.

7. Raupp P, Hassan JA, Varughese M and Kristiansson B: Henna causes life threatening haemolysis in glucose-6-phosphate dehydrogenase deficiency. Arch Dis Child 85: 411-412, 2001.

8. Kandil HH, Al-Ghanem MM, Sarwat MA and Al-Thallab FS: Henna (Lawsonia inermis Linn.) inducing haemolysis among G6PD-deficient newborns. A new clinical observation. Ann Trop Paediatr 16: 287-291, 1996. 
9. Chan TK, Todd D and Tso SC: Drug-induced haemolysis in glucose-6-phosphate dehydrogenase deficiency. Br Med J 20: 1227-1229, 1976.

10. Bashan N, Peleg N and Moses SW: Attempts to predict the hemolytic potential of drugs in glucose-6-phosphate dehydrogenase deficiency of the Mediterranean type by an in vitro test. Isr J Med Sci 24: 61-64, 1988.

11. Li AM, Hui J, Chik KW, Li CK and Fok TF: Topical herbal medicine causing haemolysis in glucose-6-phosphate dehydrogenase deficiency. Acta Paediatr 91: 1012, 2002.

12. Senanayake N and Sanmuganathan PS: Acute intravascular haemolysis in glucose-6-phosphate dehydrogenase deficient patients following ingestion of herbal broth containing Acalypha indica. Trop Doct 26: 32, 1996.

13. Kuliszkiewicz-Janus M, Tyran W and Szajerka G: Haemolytic crises caused by Hoya carnosa in a patient with G6PD deficiency. Acta Haematol Pol 23: 63-67, 1992.

14. Globerman H, Navok T and Chevion M: Haemolysis in a G6PD-deficient child induced by eating unripe peaches. Scand J Haematol 33: 337-341, 1984.

15. Fujiki H: Green tea: health benefits as cancer preventive for humans. Chem Rec 5: 119-132, 2005

16. Yang CS, Maliakal $P$ and Meng X: Inhibition of carcinogenesis by tea. Annu Rev Pharmacol Toxicol 42: 25-54, 2002.

17. Vita JA: Polyphenols and cardiovascular disease: effects on endothelial and platelet function. Am J Clin Nutr 81 (Suppl 1): S292-S297, 2005.

18. Vita JA: Tea consumption and cardiovascular disease: effects on endothelial function. J Nutr 133: S3293-S3297, 2003.

19. Weinreb O, Mandel S, Amit T and Youdim MB: Neurological mechanisms of green tea polyphenols in Alzheimer's and Parkinson's diseases. J Nutr Biochem 15: 506-516, 2004.

20. Mandel S and Youdim MB: Catechin polyphenols: neurodegeneration and neuroprotection in neurodegenerative diseases. Free Radic Biol Med 37: 304-317, 2004.

21. Liao J, Yang GY, Park ES, et al: Inhibition of lung carcinogenesis and effects on angiogenesis and apoptosis in A/J mice by oral administration of green tea. Nutr Cancer 48: 44-53, 2004.

22. Jia X, Han C and Chen J: Effects of tea on preneoplastic lesions and cell cycle regulators in rat liver. Cancer Epidemiol Biomarkers Prev 11: 1663-1667, 2002.

23. Kavanagh KT, Hafer LJ, Kim DW, et al: Green tea extracts decrease carcinogen-induced mammary tumor burden in rats and rate of breast cancer cell proliferation in culture. J Cell Biochem 82: 387-398, 2001

24. Uesato S, Kitagawa Y, Kamishimoto M, Kumagai A, Hori H and Nagasawa $\mathrm{H}$ : Inhibition of green tea catechins against the growth of cancerous human colon and hepatic epithelial cells. Cancer Lett 170: 41-44, 2001.

25. Lin JK, Liang YC and Lin-Shiau SY: Cancer chemoprevention by tea polyphenols through mitotic signal transduction blockade. Biochem Pharmacol 58: 911-915, 1999.

26. Yang GY, Liao J, Li C, et al: Effect of black and green tea polyphenols on c-jun phosphorylation and $\mathrm{H}_{2} \mathrm{O}_{2}$ production in transformed and non-transformed human bronchial cell lines: possible mechanisms of cell growth inhibition and apoptosis induction. Carcinogenesis 21: 2035-2039, 2000.

27. Vinson JA, Teufel K and Wu N: Green and black teas inhibit atherosclerosis by lipid, antioxidant, and fibrinolytic mechanisms. J Agric Food Chem 52: 3661-3665, 2004.

28. Levites Y, Weinreb O, Maor G, Youdim MB and Mandel S: Green tea polyphenol (-)-epigallocatechin-3-gallate prevents Nmethyl-4-phenyl-1,2,3,6-tetrahydropyridine-induced dopaminergic neurodegeneration. J Neurochem 78: 1073-1082, 2001.

29. Nie G, Jin C, Cao Y, Shen S and Zhao B: Distinct effects of tea catechins on 6-hydroxydopamine-induced apoptosis in PC12 cells. Arch Biochem Biophys 397: 84-90, 2002.

30. Nobre Junior HV, Cunha GM, Maia FD, Oliveira RA, Moraes MO and Rao VS: Catechin attenuates 6-hydroxydopamine (6-OHDA)induced cell death in primary cultures of mesencephalic cells. Comp Biochem Physiol C Toxicol Pharmacol 136: 175-180, 2003.

31. Bonner MR, Rothman N, Mumford JL, et al: Green tea consumption, genetic susceptibility, PAH-rich smoky coal, and the risk of lung cancer. Mutat Res 582: 53-60, 2005.

32. Michels KB, Willett WC, Fuchs CS and Giovannucci E: Coffee, tea, and caffeine consumption and incidence of colon and rectal cancer. J Natl Cancer Inst 97: 282-292, 2005.
33. Tavani A and La Vecchia C: Coffee, decaffeinated coffee, tea and cancer of the colon and rectum: a review of epidemiological studies, 1990-2003. Cancer Causes Control 15: 743-757, 2004.

34. Elbling L, Weiss RM, Teufelhofer O, et al: Green tea extract and (-)-epigallocatechin-3-gallate, the major tea catechin, exert oxidant but lack antioxidant activities. FASEB J 19: 807-809, 2005.

35. Chai PC, Long LH and Halliwell B: Contribution of hydrogen peroxide to the cytotoxicity of green tea and red wines. Biochem Biophys Res Commun 304: 650-654, 2003.

36. Weisburg JH, Weissman DB, Sedaghat $\mathrm{T}$ and Babich $\mathrm{H}$ : In vitro cytotoxicity of epigallocatechin gallate and tea extracts to cancerous and normal cells from the human oral cavity. Basic Clin Pharmacol Toxicol 95: 191-200, 2004.

37. Malik A, Azam S, Hadi N and Hadi SM: DNA degradation by water extract of green tea in the presence of copper ions: implications for anticancer properties. Phytother Res 17: 358-363, 2003.

38. Azam S, Hadi N, Khan NU and Hadi SM: Prooxidant property of green tea polyphenols catechin and epigallocatechin-3gallate: implications for anticancer properties. Toxicol in Vitro 18: 555-561, 2004.

39. Raza H and John A: Green tea polyphenol epigallocatechin-3gallate differentially modulates oxidative stress in PC12 cell compartments. Toxicol Appl Pharmacol 207: 212-220, 2005.

40. Giustarini D, Dalle-Donne I, Colombo R, Milzani A and Rossi R: An improved HPLC measurement for GSH and GSSG in human blood. Free Radic Biol Med 35: 1365-1372, 2003.

41. Chen Z, Zhu QY, Tsang D and Huang Y: Degradation of green tea catechins in tea drinks. J Agric Food Chem 49: 477-482, 2001.

42. Evelyn KA and Malloy HT: Microdetermination of oxyhemoglobin, methemoglobin, and sulfhemoglobin on a single sample of blood. J Biol Chem 126: 655-662, 1938.

43. Hseu YC, Chang WC, Hseu YT, et al: Protection of oxidative damage by aqueous extract from Antrodia camphorata mycelia in normal human erythrocytes. Life Sci 71: 469-482, 2002.

44. Mulder TP, Rietveld AG and van Amelsvoort JM: Consumption of both black tea and green tea results in an increase in the excretion of hippuric acid into urine. Am J Clin Nutr 81 (Suppl 1): S256-S260, 2005.

45. Miura YH, Tomita I, Watanabe T, Hirayama T and Fukui S: Active oxygens generation by flavonoids. Biol Pharm Bull 21: 93-96, 1998 .

46. Akagawa M, Shigemitsu T and Suyama K: Production of hydrogen peroxide by polyphenols and polyphenol-rich beverages under quasi-physiological conditions. Biosci Biotechnol Biochem 67: 2632-2640, 2003.

47. Hayakawa F, Ishizu Y, Hoshino N, Yamaji A, Ando T and Kimura T: Prooxidative activities of tea catechins in the presence of $\mathrm{Cu}^{2+}$. Biosci Biotechnol Biochem 68: 1825-1830, 2004.

48. Higdon JV and Frei B: Tea catechins and polyphenols: health effects, metabolism, and antioxidant functions. Crit Rev Food Sci Nutr 43: 89-143, 2003.

49. Lambert JD and Yang CS: Mechanisms of cancer prevention by tea constituents. J Nutr 133: S3262-S3267, 2003.

50. Kazi A, Smith DM, Daniel K, et al: Potential molecular targets of tea polyphenols in human tumor cells: significance in cancer prevention. In Vivo 16: 397-403, 2002.

51. Rizvi SI, Zaid MA, Anis R and Mishra N: Protective role of tea catechins against oxidation-induced damage of type 2 diabetic erythrocytes. Clin Exp Pharmacol Physiol 32: 70-75, 2005.

52. Lee MJ, Maliakal P, Chen L, et al: Pharmacokinetics of tea catechins after ingestion of green tea and (-)-epigallocatechin-3gallate by humans: formation of different metabolites and individual variability. Cancer Epidemiol Biomarkers Prev 11: 1025-1032, 2002.

53. Chow HH, Cai Y, Alberts DS, et al: Phase I pharmacokinetic study of tea polyphenols following single-dose administration of epigallocatechin gallate and polyphenon E. Cancer Epidemiol Biomarkers Prev 10: 53-58, 2001.

54. Chow HH, Cai Y, Hakim IA, et al: Pharmacokinetics and safety of green tea polyphenols after multiple-dose administration of epigallocatechin gallate and polyphenon $\mathrm{E}$ in healthy individuals. Clin Cancer Res 9: 3312-3319, 2003.

55. Henning SM, Niu Y, Liu Y, et al: Bioavailability and antioxidant effect of epigallocatechin gallate administrated in purified form versus as green tea extract in healthy individuals. J Nutr Biochem 16: 610-616, 2005. 